\title{
TECHNOLOGY OF HEAT TREATING-STRAIGHTENING OF LONG SHAFTS WITH LOW RIGIDITY
}

\author{
Antoni Świć1, Aleksandr Draczew² ${ }^{2}$ Arkadiusz Gola ${ }^{3}$ \\ 1 Institute of Technological Systems of Information, Lublin University of Technology, Nadbystrzycka Street 36, \\ 20-618 Lublin, Poland, e-mail: a.swic@pollub.pl \\ 2 Faculty of TM, Togliatti State University, 12 Belorusskaia Street 445021, Togliatti, Russia \\ 3 Department of Enterprise Organization, Lublin University of Technology, Nadbystrzycka Street 38, 20-618 \\ Lublin, Poland, e-mail: a.gola@pollub.pl
}

Received: 2016.04.22

Accepted: 2016.07.04

Published: 2016.09.01

\begin{abstract}
The paper presents a new method of heat treating-straightening of long shafts with low rigidity. Analytical relationships for the determination of rectilinearity of shaft axis in heat treating-straightening are presented. A fixture for heat treating-straightening of shafts was developed. The experiment conducted as well as the calculations confirm high effectiveness of the developed method of heat treating-straightening of long shafts with low rigidity. Application of the developed technology of heat treatingstraightening permits minimisation of the value of deflection of semi-finished product and stabilisation of the level of residual longitudinal stress, which results in enhanced operational accuracy of long shafts with low rigidity, improved quality and operation parameters of finished products.
\end{abstract}

Keywords: heat treating-straightening, long shaft with low rigidity.

\section{INTRODUCTION}

Shaft-type parts with low rigidity are used in many contemporary machines, fixtures and other devices $[1,6,7,8,10,11,12,13,14]$. The continuous growth of production of low-rigidity shafts is determined by the growing production of precision machines. The disproportions in the design parameters of shafts with low rigidity generate serious difficulties in their production, caused e.g. by the following:

- considerable elastic and plastic deformations at all stages of machining, assembly and operation of parts;

- low resistance to vibrations and varied flexibility of elements of technological systems of machining,

- considerable effect of technological heredity on operational reliability,

- warping of semi-finished products caused by uneven residual stresses generated at all stages of machining,

- low thermal stability of parts.

The negative effect of those factors in the production of long shafts with low rigidity leads, among other things, to the necessity of lowering of milling parameters, lowering of productivity, and also to incomplete utilisation of the performance of machine tools and of service life of tools.

Analysis of production experience in the area of manufacturing long shafts with low rigidity in unit production, short-series production and series production demonstrated that the traditional methods of machining of rigid parts are not effective in the production of shafts with low rigidity, therefore, in practice, their production is conducted at lowered milling parameters and with the use of the operation of manual lapping, which significantly reduces the efficiency of their production. There is also the necessity of applying 
complex technological operations of stabilising treatments, determined by the fact that changes in form and dimensions require changes of the input parameters and lead to a reduction of reliability of precision machines. Reliability should be ensured under conditions of long-term operation at constant and variable temperatures $\left(-50^{\circ}\right.$ to $\left.+100^{\circ} \mathrm{C}\right)$. It is known that the fullest dimensional characteristic of stability of a material in time is the value of the maximum stress that does not undergo relaxation over a long time, that is referred to as the conventional relaxation limit. That value is recommended to be used as the basic characteristic of material stability in the machine building industry $[3,5,9]$.

In view of the above, improvement of technological processes of production of long shafts with low rigidity, permitting the achievement of required parameters at considerably increased efficiency, and thus significant reduction of energy consumption in their manufacture, is an important and current problem.

\section{ANALYTICAL DETERMINATION OF RECTILINEARITY OF SHAFT AXIS IN HEAT TREATING-STRAIGHTENING}

The production of long shafts with low rigidity is conducted with the use of semi-finished products of bar material that is characterised by considerable curvature. Prior to machining such bars need to be straightened to achieve rectilinearity of ca. $0.5 \mathrm{~mm}$ per 1 meter $[2,4,14]$, which allows, in turning, to obtain a shaft with the given tolerance for shaft axis curvature. The drawback of straightening is the introduction of uneven residual stresses along the longitudinal section of the semi-finished product, that later, when a layer of the material is removed in the process of machining, cause the appearance of a bending moment and a corresponding change in the rectilinearity of the shaft axis [14].

Axial straightening is a frequently applied operation. During the drawing of a cylindrical semifinished product, all fibres are brought to the limit of plasticity, therefore the residual axial stresses existing before are relieved. In the course of axial straightening, the residual stresses disappear completely at final deformation of $0.5-1 \%[1,4,11]$.

The straightening of a long shaft with low rigidity, made of austenitic steel X10CrNi18-8, combined with the operation of quench hardening (to improve the corrosion resistance of the steel - tempering is not required in this case), was conducted in a device for heat treating- straightening. Austenitic steels have a high coefficient of thermal expansion, so to generate the axial straightening force after the completion of semi-finished product heating for the hardening its end are clamped in a fixture made of a steel with thermal expansion coefficient lower than that of the material of the semi-finished product, and cooling of the device with the clamped semi-finished product is performed. As a result of the difference in the expansion coefficients, during the cooling an axial force is generated that, acting on the semifinished product, causes its axial straightening. The fixture was a rigid tube of steel C25, with apertures for the coolant. The clamps were installed at the ends of the fixture.

In the process under analysis, the concept of quality straightening is taken to mean such straightening in which, under the effect of axial straightening force, in each fibre in any cross section of the semi-finished product the stresses generated do not exceed the limit of plasticity of the material in compression. During the subsequent drawing, in any cross-section over the entire surface area the stresses generated are not lower than the limit of plasticity.

The maximum initial deflection of a semifinished product is understood as such an initial deflection at which in the outermost compressed fibre the compression stresses generated are not greater than the limit of plasticity, at a temperature corresponding to the deflected shaft axis approaching a straight line. In the opposite case, in the cross-section of the semi-finished product a "compressive" strain appears that, at further drawing up to the limit of plasticity, does not fully retreat - Bauschinger effect. The effect is an asymmetrical zone of strain which is reflected in residual stress distribution asymmetrical to the axis of symmetry of the cross-section, which then has en effect on the rectilinearity of the shaft. It was determined that the axis of semi-finished product of a long shaft is described well by an quadratic equation of a parabola:

$$
f(z)=\frac{4 \delta_{u \max }}{l} \cdot z \cdot\left(1-\frac{z}{l}\right)
$$

where: $\delta_{\text {umax }}-$ maximum initial deflection of semi-finished product,

$l$ - distance between centre-points of extreme cross-sections of shaft. 
The maximum stress formed in the outermost fibre at the drawing of bent shaft axis to the straight line is determined from the relation:

$$
\sigma_{\max }=\frac{\left(\delta_{u \max } \cdot F\right)}{W_{x}}
$$

where: $F$ - axial force,

$W_{x}$ - bending strength index.

The value of force $F$ is determined based on relation [14] which can be transformed to the expression:

$$
F=\frac{3 \pi \cdot D^{4} \cdot E}{20 \cdot l^{2}}
$$

where: $D$ - diameter of semi-finished shaft,

$E$ - Young modulus. tain:

Designating the ratio of $l$ to $D$ as $K_{0}$, we ob-

$$
\delta_{u \max } \leq \frac{5 K_{0}^{2} \cdot D \cdot R_{e}}{24 E}
$$

Maximum compressive stresses appear in a fibre when the shaft is cooled down by temperature $\Delta T$, corresponding to its shortening to the value of the maximum initial deflection, and in relation with changes of $\sigma_{p}$ and $E$ with the lowering of temperature $\left(R_{e}=R_{t}(t), E=E(t)\right)$, and therefore relation (4) can be transformed to:

$$
\delta_{u \max } \leq \frac{5 K_{0}^{2} \cdot D \cdot R_{e}(t-\Delta T)}{24 E(t-\Delta T)}
$$

When shaft temperature is reduced by $\Delta T$, its length is shortened by:

$$
\Delta l=\Delta \alpha(t) \cdot l \cdot \Delta T
$$

where: $\Delta \alpha(t)$ - difference of expansion coefficients of the material of the semi-finished product and the fixture, functionally dependent on temperature.

The shortening of shaft length $\Delta l$ in cooling should then allow the straightening of the deflected axis, that means:

$$
\Delta l=\delta_{o w}+2 \delta_{l c}
$$

where: $\delta_{o w}$ - distance required for the "choice" of semi-finished product deflection, defined as:

$$
\delta_{\text {ow }}=\frac{8 \cdot \delta_{u \max }^{2}}{3 l}
$$

where: $\delta_{l c}-$ clearance between the butting face of the fixture and the face of the lock cog, equal to:

$$
\delta_{l c}=\frac{2 D_{w} \cdot \delta_{u \max }}{l}
$$

where: $D_{w}-$ diameter of the cogs.

Denoting the ratio of the diameter of the lock $\operatorname{cog}$ (or grub screw) to the diameter of the semifinished product as $C$, we can write:

$$
\Delta T=\frac{1}{\Delta \alpha(t) \cdot l^{2}}\left(\frac{8}{3} \delta_{u \max }^{2}+4 C \cdot D \cdot \delta_{u \max }\right)
$$

After the substitution of relation (10) to (5) and solving relative to $\delta_{\max }$, we determine the maximum initial deflection of the semi-finished product in relation to its geometry and to the physical properties of the material.

In particular, in the case of semi-finished products of steel X10CrNi18-8 and a fixture of steel C 25 we obtained:

$\Delta \alpha=1,43 \cdot t^{-0,205}, E=2688 \cdot t^{-0,075}, R_{e}=84,1 \cdot t^{-0,314}$

where: $t$ - temperature of heating.

Comparison of calculated values of initial deflection with data on true output deflection of semi-finished products of steel X10CrNi18-2 with diameters from 20 to $80 \mathrm{~mm}$ and length to diameter ratios from 30 to 80 indicates that there can be output semi-finished products with initial deflection greater than the output deflection. Therefore semi-finished products for long shafts should be selected prior to the process on the basis of the initial deflection, taking into account relation (5). Semi-finished products for shafts of steel X10CrNi18-2, with length of $1050 \mathrm{~mm}$ and diameter of $30 \mathrm{~mm}$, should have quality output deflection not greater than $3.4 \mathrm{~mm}$; in practice we encounter semi-finished products with similar dimensions and deflection of up to $6 \mathrm{~mm}$.

The deflection of a semi-finished product that can be eliminated with the help of heat treatingstraightening, taking into account that the output deflection cannot be greater than the maximum quality value, is determined as follows: during the cooling the shortening of the semi-finished product should be less than the sum of elongations:

$$
\Delta l=\delta_{o w}+2 \delta_{l c}+\delta_{s p}+\delta_{w p}
$$

where: $\delta_{s p}$ - shrinkage of fixture as a result of load caused by the reduction in the length of 
the semi-finished product, equal:

$$
\delta_{s p}=\frac{R_{e} \cdot l}{E_{u} \cdot K_{s}}
$$

where: $R_{e}$ - limit of plasticity of material of semifinished product at $20^{\circ} \mathrm{C}$,

$E_{u}$ - modulus of longitudinal elasticity of material of fixture at $20^{\circ} \mathrm{C}$,

$K_{s}$ - ratio of fixture stiffness to stiffness of semi-finished product,

$\delta_{w p}-$ elongation of semi-finished product, at which the stress in outermost compressed fibre was not lower than the limit of plasticity of shaft material in tension, i.e.

$$
\delta_{w p}=\frac{\left(\sigma_{k}+R_{e}\right) \cdot l}{E_{20^{0}}}
$$

$\sigma_{k}-$ stresses in outermost fibre of crosssection of maximum deflection of semi-finished product, generated during the drawing of deflected axis to the straight line.

In conformance with (4), the relation for the determination of $\sigma_{k}$ has the form:

$$
\sigma_{k}=\frac{24 D \cdot E_{t} \cdot \delta_{u \max }}{5 l^{2}}
$$

where: $E_{t}$ - modulus of longitudinal elasticity of shaft material at temperature of heating.

After solving relation (11) relative to $\delta_{\max }$, we obtain:

$\delta_{u \max }=-D\left(0,9 \frac{E_{t}}{E_{20}^{0}}+\frac{3}{4} C\right)+$

$+D \frac{1}{2} \sqrt{\left(1,8 \frac{E_{t,}}{E_{20}^{0}}+1,5 C\right)^{2}+1,5 K_{0}^{2} \frac{\sigma_{p}}{E_{20}^{0}}\left(\frac{\Delta \alpha \cdot t \cdot E_{20}^{0}}{R_{e}}-\frac{E_{20}^{0}}{E_{u} K_{S}}-1\right)}$

where: $t$ - temperature of heating,

$\Delta \alpha$ - difference of expansion coefficients of semi-finished product and fixture material within temperature range from $20^{\circ} \mathrm{C}$ to temperature of heating.

Based on the analysis of initial deflections of semi-finished products with various dimensions, and on the calculation of the maximum correcting deflection in the fixture, we can perform the axial straightening of the shafts, with simultaneous heat treating, and the correction of the initial deflection of the semi-finished products, by drawing fibres in any cross-section up to the limit of plasticity and generating in the material of the semi-finished products residual stresses symmetrical relative to the shaft axis.

\section{METHOD OF HEAT TREATING-DTRAIGH- TENING OF LONG SHAFTS WITH LOW RIGIDITY}

Analysis of the technology of manufacturing of long shafts with low rigidity, and in particular of the operation of heat treating- straightening [6, $7,13]$, revealed that the drawback of the known technological approaches is the impossibility of keeping the product - shaft - at the state of tension when the temperature is decreased to $20^{\circ} \mathrm{C}$, as the fixture is compressed faster than the shaft. Because the walls of the fixture (layered tube or sleeve) are thin (fixture cools down several-fold faster), a gap is formed between the face of the dissected clamping sleeve, which causes the release of the product during cooling, and the appearance of an uneven distribution of inner compressive forces. The heat at the ends of the semifinished product is carried away faster due to the contact of the product ends with the nut, which leads to the uneven distribution of residual stresses on the length of the product.

The developed technology of heat treating - straightening of log shafts with low rigidity permits increased accuracy and stability of geometric parameters, and increased operational accuracy of finished products as a result of generation of uniform residual stresses, variable according to the sign, over the entire length of the semi-finished product.

In the case under consideration, part 1 undergoes preliminary machining on a lathe with the use of steadies. The following outlines of working profiles 2 are formed (Fig. 1):

- threaded, in the determination of the pitch we should take into account: the limit strength of the material, the size of the cross-section of the semi-finished product, the depth of thread cutting (its inner diameter) - it should not be greater than the material allowance for machining;

- stepped-diameter, in which the difference between the outer and inner diameters is also dependent on the limit strength of the material and on the cross-section of the semi-finished product, and should not exceed the material allowance for machining.

When machining/treating a part with thread, expansion sleeves 3 are screwed onto the semifinished product, and in the case of stepped-diameter parts expansion sleeves 3 are installed like a split bearing bushing (the sleeve consists of two 
parts). The sleeves are made of a material with linear expansion coefficient $\alpha_{t}$ is lower than the linear expansion coefficient of the material of the part $\alpha_{\mathrm{cz}}$.

The length of the sleeve is determined from the condition of equivalence of parts of the product on which the sleeve is installed, and the condition of minimisation of deflection.

To achieve compression uniformity along the axis of the part, and to achieve the required stiffness of the part compressed, the length ratio $1_{1}=1_{2}, 1 / \mathrm{d} \leq 8$ was adopted. The sleeves 3 are provided with apertures 9 , with such shapes and distribution as to ensure the inflow of coolant at any relative mutual positioning of two neighbouring sleeves.

Part 1 with expansion sleeves 3 (threaded if the part is also provided with thread, or twoelement in the case of stepped-diameter parts) is placed (with a predetermined value of clearance) in the multi-layered cylinder 4 and aligned relative to its lower and upper face. Cylinder 4 is made of a material with linear expansion coefficient equal to that of the sleeves (to eliminate jamming due to temperature deformation), and filled with filler 5. Filler 5 can have a different values of thermal expansion coefficient (e.g. river sand mixed with cast iron chips).

The body of cylinder 4 is multi-layered, each layer having an additional volume filled a material with a lower thermal expansion coefficient. The material chosen for the cylinder has a higher linear expansion coefficient than that of the material of the semi-finished product. In the multilayer body of the cylinder ports are provided, in the longitudinal and lateral directions, in which

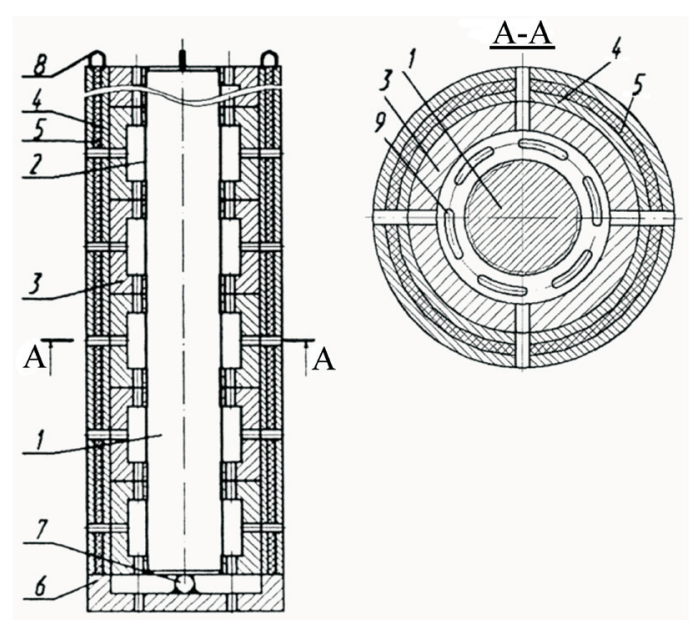

Fig. 1. Device for heat treating- straightening of long shafts with low rigidity sleeves are installed, made of the same material as the cylinder. The inner diameters of the sleeves and their number are determined from the condition of the technological process (hardening, tempering etc.) and taking into account the geometric parameters of the semi-finished product (e.g. smooth shaft or stepped-diameter shaft). Part fixing can be realized in two variants:

- the shaft is aligned relative to the lower face by means of a spherical surface, mounted rigidly to cover 6 on the lower face, and thus the shaft is supported by its lower end the spherical surface, which guarantees point-wise contact with the cylinder;

- the shaft is aligned relative to two faces by means of two spherical surfaces 7 , rigidly attached to covers 6 , on the lower and upper faces. With this method of fixing the element is rigidly axially connected with the cylinder.

Four eye rings 8 are welded to the upper part of cylinder 4 , to provide means of suspending the whole device. To avoid deflection of part 1 , caused by the effect of stresses generated in the course of heating-cooling of the system: part - expansion sleeves - cylinder, the clearance between sleeves 3 and cylinder 4 should be minimal, just enough to allow the device to work without jamming.

The assembled device is placed in a shaft furnace and heated, in accordance with the technology of heat treating, to the temperature of hardening or tempering, and soaked at that temperature until the whole part is heated. During heating, the part expands in length to a greater extent than the sleeves and the cylinder, due to the difference in the values of linear expansion coefficients. Plastic deformation of the part, exceeding the limit of proportionality, i.e. the limit of Hooke's law, is achieved as a result of suitable choice of numerical values of positive difference between the thermal linear expansion coefficients of the part and the sleeves. During heating, axial plastic deformation beyond the limit of proportionality (Hooke's law), eliminates the technological heredity from the preceding operations. Apart from that, as a result of the effect of axial loads, strain hardening of the material of the part takes place equalisation in internal micro-cracks.

The cylinder with the semi-finished product is cooled down to a certain temperature, the difference between the cooling time of the semifinished product and the cylinder is changed, maintaining the axial state of stresses of the 
material of the semi-finished product, until the complete cooling is achieved; simultaneously, curved semi-finished products are straightened. As opposed to the known methods, in which plastic deformation of the product takes placer during the cooling, the cylinder cools down faster than the shaft, and residual stresses have a local character; the essence of this technology consists in the reversal of the sequence of technological treatments.

In the presented technology, plastic deformations take place during heating at a specific rate, the cylinder expanding to a greater extent than the semi-finished product, by the value of the linear thermal coefficient and the difference in the length of the cylinder and the part. During cooling, the rate of cylinder cooling is at least five-fold lower than the rate of cooling of the semi-finished product (the semi-finished product should cool down at a rate minimum five-fold slower than the fixturedepending on the type of cooling agent used: oil, water, air). During the cooling, in a semi-finished product subjected to axial loads residual stresses are generated, alternating according to sign, along the entire length and uniform in the cross-section, which precludes warping of finished parts during their operation.

To expand the technological capabilities of heat treating-straightening, the multi-layer cylinder is assembles from sections, so that in the case of need to increase the length of semi-finished products and values of plastic deformations the length of the cylinder is increased by increasing the number of sections in the assembly.

Comparison of internal stresses in the shaft before and after the application of heat treatingstraightening is presented in Figure 2. The strength characteristics of the parts are also improved.

The application of the new technology of heat treating-straightening permits minimisation of the value of deflection of semi-finished product and stabilisation of the level of longitudinal residual stresses, which results in enhanced operational accuracy of the finished element, e.g. long shafts with low rigidity, and improvement of quality of finished products.

\section{EXAMPLE OF PRACTICAL APPLICATION OF THE DEVICE}

The experiment was conducted for a shaft semi-finished product made of steel X17CrNi16-2 and cylinder and sleeves of steel $41 \mathrm{Cr} 4$. Temperature expansions were calculated from the relation:

$$
\Delta L=\alpha_{c z}\left(T^{\circ}\right) \cdot T^{\circ} \cdot L-\alpha_{t}\left(T^{\circ}\right) \cdot T^{\circ} \cdot L
$$

where: $\Delta L$ - difference of elongation of shaft semi-finished product and sleeves, $T^{\circ}$ - temperature of heating, $L-$ length of sleeves and shaft section.

The value of plastic deformations is determined from the relation:

$$
\varepsilon=\frac{\Delta L}{L}
$$

at: $L=200 \mathrm{~mm}, T^{\circ}=1050^{\circ} \mathrm{C}, \alpha_{c z}=18.5 \cdot 10^{-6} \mathrm{~mm} /$ $\mathrm{mm}$ stop, $\alpha_{t}=12.8 \cdot 10^{-6} \mathrm{~mm} / \mathrm{mm}$ stop: $\Delta L=18,5 \cdot 10^{-6} \cdot 1050 \cdot 200-12.8 \cdot 10^{-6} \cdot 1050 \cdot 200=$ $=1,197 \mathrm{~mm}$.

The value of plastic deformation:

$$
\varepsilon=\frac{1,197}{200}=0,5985 \%
$$

Time of cooling is calculated at the following parameters: shaft diameter $40 \mathrm{~mm}$, inner diameter of cylinder $160 \mathrm{~mm}$, outer $260 \mathrm{~mm}$, filler - sand mixed with cast iron chips, cooling agent - oil with temperature of $30^{\circ}$. The time of cooling is determined from the relation:

$$
\tau=\frac{F_{0} \cdot d^{2} \cdot \gamma \cdot c}{4 \lambda} \mathrm{s}
$$

Cooling time of the cylinder is determined by solving the equation:

$$
\frac{\theta_{0}}{\theta^{\prime}}=\Phi_{0}\left(B_{i}, F_{0}\right)
$$

where: $F_{0}=\alpha / \mathrm{r}^{2}-$ Fourier criterion, determined as a function of relative temperatures $\theta_{0} / \theta$, $B_{i}=B_{0} / \lambda_{\text {ekw. }}$ - Biot number, $r$ - radius of long shaft (in the case given the shaft is represented as an infinitely long cylinder with radius $\delta$ ), $\lambda_{\text {ekw. }}$ - equivalent thermal conductivity of the system: sleeve-multilayered cylinder, $B_{0}$ - coefficient of heat transfer from the environment to the surface of a body, $\gamma$ - specific gravity of the material.

From the choice of material for the sleeves and the cylinder relative to the material of the shaft, over the whole cycle of heat treating the difference between the thermal expansion coefficients $\alpha_{c z}$ and $\alpha_{t}$ is positive. 
The experiment and the calculations confirm the effectiveness of the method developed for heat treating-straightening of long shafts with low rigidity.

\section{CONCLUSIONS}

The paper presents a method for the achievement of form and dimensional stability of shafttype parts of low rigidity, used extensively especially in precision systems. Shaft axis rectilinearity in heat treating-straightening was determined analytically, a new technology for heat treatingstraightening of long shafts with low rigidity was developed, and an example of its realization is presented; the method permits increased operational accuracy of finished products as a result of generation of uniform residual stresses, alternating according to the sign, on the entire length of the semi-finished product.

Relations were developed for analytical determination of shaft axis rectilinearity in heat treating-straightening, permitting axial straightening of shaft semi-finished products with simultaneous heat treating and correction of their ini-
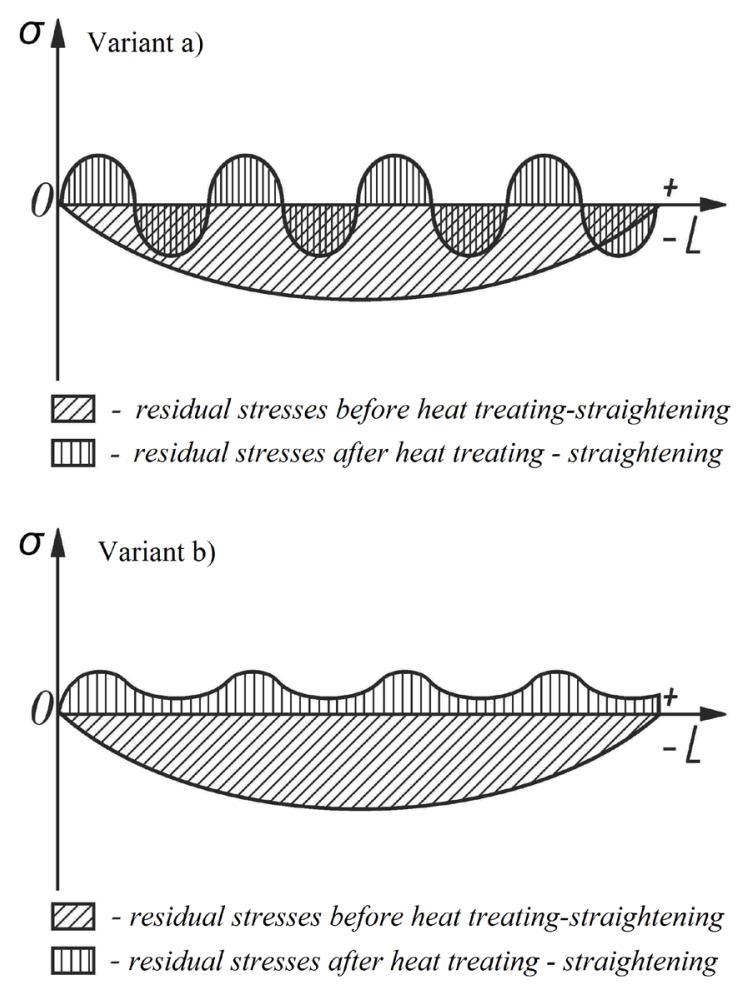

Fig. 2. Changes in the level of residual stresses in the part before and after heat treating-straightening: a) variant of part alignment and fixing relative to lower face via spherical surface; b) variant of part alignment and fixing relative to two faces via two spherical surfaces tial deflection, as a result of fibre tension in any cross-section up to the limit of plasticity and the generation of residual stresses, symmetrical to the axis, in the material of the semi-finished product.

The developed device and technology of heat treating-straightening of long shafts with low rigidity permits: increased accuracy and stability of geometric parameters; improved operational accuracy of finished products as a result of generation of uniform residual stresses, alternating according to the sign, on the entire length of the semi-finished product; minimisation of the deflection of the semi-finished product; stabilisation of the level of longitudinal residual stresses, which results in improved operational accuracy of the finished product, e.g. long shaft with low rigidity, and improved quality of finished products.

\section{REFERENCES}

1. Halas W., Taranenko V., Swic A., Taranenko G.: Investigation of influence of grinding regimes on surface tension state. Lecture Notes in Computer Science), 5027 LNAI, 2008, 749-756.

2. Jaworski, J., Kluz R., Trzepieciński T.: Operational tests of wear dynamics of drills made of low-alloy high-speed HS2-5-1 steel. Eksploatacja i Niezawodnosc - Maintenance and Reliability, 18 (2), 2016, 271-277.

3. Jaworski J., Trzepieciński T.: Research on durability of turning tools made of low-alloy high-speed steels Kovove Materialy - Metallic Materials, 54 (1), 2016, 17-25.

4. Li H., Shin Y. C.: Integration of thermo-dynamic spindle and machining simulation models for a digital machining system. The International Journal of Advanced Manufacturing Technology, 40 (7-8), 648-661.

5. Lin C.W., Tu J. F., Kamman J.: An integrated thermo-mechanical-dynamic model to characterize motorized machine tool spindles during very high speed rotation. International Journal of Machine Tools and Manufacture, 43 (10), 2003, 1035-1050.

6. Draczew O., Świć A., Taranenko W., Taranenko G.: Modelowanie układu dynamicznego obróbki cieplno-mechanicznej wałów o małej sztywności. Postępy Nauki i Techniki, 5, 2010, 71-84.

7. Świć A., Draczew A., Gola A.: Method of achieving accuracy of thermo-mechanical treatment of low-rigidity shafts. Advances in Science and Technology Research Journal, 10 (29), 2016, 62-70

8. Świć A., Gola A., Wołos D.: A method for increasing the economic effectiveness of the low rigidity 
shafts, Actual Problems of Economics, 11 (161), 2014, 469-477.

9. Świć A., Gola A.: Economic analysis of casing parts production in a flexible manufacturing system, Actual Problems of Economics, 3 (141), 2013, 526-533.

10. Świć A., Taranenko W., Gola A.: Analysis of the process of turning of low-rigidity shafts, Applied Mechanics and Materials, 791, 2015, 238-245.

11. Świć A, Taranenko W, Szabelski J.: Modelling dynamic systems of low-rigid shaft grinding. Eksploatacja i Niezawodność - Maintenance and Reli- ability, 2 (50), 2011, 13-24.

12. Świć A., Wołos D., Zubrzycki J., Opielak M., Gola A., Taranenko V.: Accuracy control in the machining of low rigidity shafts, Applied Mechanics and Materials, 613, 2014, 357-367.

13. Taranenko G, Taranenko W, Świć A, Szabelski J.: Modelling of dynamic systems of low-rigidity shaft machining. Eksploatacja i Niezawodność Maintenance and Reliability, 4(48), 2010, 4-15.

14. Świć A. Technologia obróbki wałów o małej sztywności. Wydawnictwo Politechniki Lubelskiej, Lublin 2009. 